\title{
A Survey of Knowledge, Attitude, and Practice of AIDS Patients with Regard to the Prevention of Disease Transmission in Yazd and Ahvaz,
}

\section{Iran}

\author{
Mohammad Hosein Baghianimoghadam, ${ }^{1}$ Maryam Saki,, ${ }^{2,}$ Ebrahim Khodkar, ${ }^{3}$ Mehrdad \\ Baghianimoghadam, ${ }^{4}$ Esmat Rahavi, ${ }^{5}$ and Nahid $\operatorname{Ardian}^{6}$ \\ ${ }^{1}$ Professor, Social Determinants of Health Research Center, Shahid Sadoughi University of Medical Sciences, Yazd, IR Iran \\ ${ }^{2} \mathrm{PhD}$ Student of Health Education and Health Promotion, School of Public Health, Yazd, IR Iran \\ ${ }^{3}$ Master of Parasitology, Jundishapur University of Medical Sciences, Ahvaz, IR Iran \\ ${ }^{4} \mathrm{MD}$, Yazd University of Medical Sciences, Yazd, IR Iran \\ ${ }^{5} \mathrm{MA}$ in Counseling, Teacher \\ ${ }^{6} \mathrm{PhD}$ Student in Research, Social Determinants of Health Research Center, Shahid Sadoughi University of Medical Sciences, Yazd, IR Iran \\ "Corresponding author: Maryam Saki, PhD Student of Health Education and Health Promotion, School of Public Health, Yazd, IR Iran. E-mail: saki@gmail.com
}

Received 2015 November 14; Revised 2016 October 24; Accepted 2016 December 04.

\begin{abstract}
Introduction: The aim of this study was to determine the knowledge, attitude, and practice of AIDS patients with regard to the prevention of disease transmission in Yazd and Ahvaz, Iran.

Methods: In this cross-sectional study, we evaluated the knowledge, attitude, and practice of 130 patients, selected via simple sampling, with regard to the prevention of disease transmission in Yazd and Ahvaz, Iran (65 cases from each city). Data were collected by researchers, using a questionnaire and a checklist. For statistical analysis, descriptive and analytical tests were performed, using SPSS version 16.

Results: In this study, the sample included 130 AIDS patients from Yazd and Ahvaz. Overall, 67.6\% of the patients were male; on the other hand, $29.2 \%$ and $32.3 \%$ of the participants from Yazd and Ahvaz were female, respectively. As the findings revealed, $44.6 \%$ and $55.4 \%$ of the patients from Yazd and Ahvaz were married, respectively. The mean scores of knowledge, attitude, and practice of the patients regarding the prevention of HIV transmission were $40.31 \pm 3.3,41.92 \pm 8.8$, and $43.28 \pm 5.3$ in Yazd, respectively. Also, the mean scores of knowledge, attitude, and practice with regard to the prevention of HIV transmission were 40.68 $\pm 3.2 .5,42.52 \pm 9.05$, and $43.24 \pm 6.08$ among patients from Ahvaz, respectively. Overall, the results showed that the knowledge, attitude, and practice of most patients were at a medium level. Also, most of the participants from Yazd (70.8\%) and Ahvaz (56.9\%) had obtained information at AIDS counseling centers.
\end{abstract}

Conclusions: The results highlighted the need to educate patients regarding the prevention of HIV transmission.

Keywords: Acquired Immunodeficiency Syndrome (AIDS), Knowledge, Attitude, Practice

\section{Introduction}

Acquired immunodeficiency syndrome(AIDS) is recognized as a global pandemic. According to the world health organization (WHO), 75 million people were infected with AIDS by 2005 (1). In 2006, nearly 57.8\% of AIDS cases were reported among 15- to 29-year-old individuals, thereby highlighting the vulnerability of young population to this disease (2). As indicated by the joint united nations program on HIV/AIDS (UNAIDS), a total of 34.2 million people lived with HIV infection in 2011, 1.7 million of whom reportedly died (3).

AIDS is a lethal disease, caused by a virus which weakens and destroys the human immune system and puts the patient at risk. According to the center for disease control and prevention, 33 regions of the United States of Amer- ica reported the statistics of AIDS and HIV in 2005. According to the statistics, 8,000 people die from AIDS each day across the world, and one person dies from AIDS-related diseases every 10 seconds (4). In 2012, about 23 million people were infected with HIV worldwide, $71 \%$ of whom lived in sub-Saharan Africa (5).

HIV infection is related to risky behaviors such as unprotected sex and drug injection. Sex is the major route of HIV transmission in the world; in fact, $85 \%$ of new HIV cases are transmitted through unsafe sexual behaviors. In Iran, transmission of the virus normally occurs through drug injections and risky sexual intercourse, respectively (6). Most cases of HIV transmission result from a failure to use efficient and accessible preventive strategies. Also, inadequate and poor coverage of prevention programs is another source of disease spread (1). 
AIDS is a health, social, and psychological crisis, affecting not only adults, but also children. In fact, AIDS is a common problem among the youth, with $85 \%$ of cases reported in developing countries. In addition, about $50 \%$ of newly infected cases are aged between 10 and 24 years. This disease mostly affects the young population and has a major destructive impact on skilled, educated, and productive individuals. Additionally, AIDS is known to affect the household composition, social function, and social capital. Therefore, preventing the spread of the disease is a great contribution to the country, resulting in the improvement of public health and sustainable development (7).

According to the center for disease control and prevention, if the basic steps are ignored in educating the youth about AIDS and virus transmission, we will be faced with an increasing number of individuals with AIDS. The first wave of AIDS epidemic in Iran, which emerged in 1987, was caused by transmission through blood and blood products. The second wave of AIDS epidemic started in 1996 1997 in Iran due to the use of shared syringes among injecting drug users. Finally, the third wave of HIV transmission resulted from high-risk sexual behaviors, threatening certain populations (8).

Considering the absence of absolute treatment methods for AIDS and strategies to treat HIV carriers, major attention should be paid to the prevention of HIV transmission. The most important way to prevent the spread of the disease in the community is education. The results of a study by Rad et al. (9) on people, referred for dental care, showed a mean knowledge score of $69.31 \%$. Based on the findings, TV was the most common source of information (67.7\%), and women's level of knowledge was significantly higher than men $(\mathrm{P}=0.031)$. In addition, there was a significant relationship between the level of knowledge and education ( $\mathrm{P}=0.0001)$. Also, $86.9 \%$ of the subjects were fearful and concerned about disease transmission during dental treatments. In the mentioned study, $48.5 \%$ of the participants believed that patients should be tested for AIDS before dental treatments.

The findings reported by Zareban et al. in a study entitled, "Efficacy of AIDS prevention training program on knowledge, attitude, and practice of Chabahar sailors", showed that $21 \%$ of sailors had sexual intercourse abroad. There was a significant difference between the scores of knowledge, attitude, and practice of the participants before and after the intervention (10). In general, promoting awareness among the youth about HIV prevention (especially prevention of HIV transmission through sex) and correcting their false beliefs are the main indicators of behavior and awareness and are the major issues in the country's AIDS control program (11).

Today, the priorities of national AIDS programs and the ministry of health and medical education are promotion of the general population's (15 to 49 years old) awareness and attitude regarding AIDS prevention and increasing the number of young people, who are familiar with proper HIV prevention and are not influenced by false beliefs about HIV transmission (8). With this background in mind, in this study, we aimed to determine the knowledge, attitude, and practice of AIDS patients regarding the prevention of AIDS transmission in Yazd and Ahvaz, Iran.

\section{Methods}

In this cross-sectional study, we evaluated the knowledge, attitude, and practice of 130 AIDS patients regarding the prevention of AIDS transmission in Yazd and Ahvaz, Iran. A total of 130 patients ( 65 cases from each city) were selected via simple sampling. According to the Cochran's formula, 130 patients were selected for this research. The study sample included all AIDS patients, who were referred to AIDS counseling centers of Yazd and Ahvaz (western regions); the only inclusion criterion was HIV infection.

The variables in this study included age, sex, education, occupation, marital status, duration of HIV infection, experiences about the disease and the community's approach, patients' experiences about their interactions with healthcare providers, and the patients' knowledge, attitude, and practice with regard to the prevention of HIV transmission. To collect data on the knowledge and attitude of the patients, we used a researcher-made questionnaire. The questionnaires were distributed by an expert in AIDS management at the counseling centers and were completed by the patients. Also, a checklist was used for collecting data about the patients' practice and behaviors.

The participants were asked to complete the questionnaire and were assured about the anonymity and confidentiality of the information. Moreover, the study subject and the questionnaire were approved by the ethics committee of Shahid Sadoughi University of Medical Sciences, Yazd, Iran.

The questionnaire included 10 questions on demographic characteristics, such as age, sex, education, occupation, and marital status. Some questions were concerned with the awareness of AIDS patients about preventive methods, and 16 questions were related to the patients' attitudes towards AIDS and ways of prevention. The practice checklist focused on the patients' healthy behaviors, including those related to the prevention of HIV transmission. Content validity of the questionnaire was confirmed by experts. Also, reliability of the questionnaire was evaluated in a preliminary study by using 20 questionnaires, which were completed by the patients (they were not included in the original study sample). 
Data were analyzed, using SPSS version 16 . To describe the data, tables of frequency and numerical descriptive indicators such as mean, standard deviation, and ratio were calculated. To compare knowledge, attitude, and practice among different age, occupation, and education groups, Pearson's correlation coefficient test was applied. Knowledge and attitude scores were calculated, based on a 100point scale (Tables 1 - 5).

Table 1. Frequency Distribution of AIDS Patients Based on Sex in Yazd and Ahvaz, $\operatorname{Iran}^{\mathrm{a}}$

\begin{tabular}{lcl}
\hline Sex & Yazd & Ahvaz \\
\hline Male & $44(67.7)$ & $44(67.7)$ \\
Female & $21(32.3)$ & $21(32.3)$ \\
Total & $65(100)$ & $65(100)$ \\
\hline
\end{tabular}

${ }^{\mathrm{a}}$ Values are expressed as No. (\%).

Table 2. Frequency Distribution of AIDS Patients Based on the Level of Education in Yazd and Ahvaz, Iran ${ }^{\mathrm{a}}$

\begin{tabular}{lcc}
\hline Level of education & Ahvaz & Yazd \\
\hline Literacy & $3(4.6)$ & $7(10.8)$ \\
\hline Primary school & $22(33.8)$ & $23(35.4)$ \\
\hline Middle school & $22(33.8)$ & $20(30.8)$ \\
\hline High school diploma & $16(24.6)$ & $15(23)$ \\
\hline University & $2(3.2)$ & $0(0)$ \\
\hline Total & $65(100)$ & $65(100)$ \\
\hline
\end{tabular}

${ }^{\mathrm{a}}$ Values are expressed as No. (\%).

Table 3. Frequency Distribution of AIDS Patients Based on Age in Yazd and Ahvaz, $\operatorname{Iran}^{\mathrm{a}}$

\begin{tabular}{lcc}
\hline Age & Ahvaz & Yazd \\
\hline$<\mathbf{2 0}$ & $1(1.5)$ & $1(1.5)$ \\
$\mathbf{2 0 - 2 4}$ & $7(10.8)$ & $3(4.6)$ \\
\hline $\mathbf{2 5 - 3 4}$ & $25(38.5)$ & $18(27.7)$ \\
\hline $\mathbf{3 5 - 4 4}$ & $17(26.2)$ & $36(55.4)$ \\
\hline $\mathbf{4 5}-\mathbf{5 4}$ & $9(13.8)$ & $7(10.8)$ \\
$>\mathbf{5 5}$ & $6(9.2)$ & $0(0)$ \\
\hline Total & $65(100)$ & $65(100)$ \\
\hline
\end{tabular}

${ }^{\mathrm{a}}$ Values are expressed as No. (\%).

\subsection{Ethical Approval}

The ethics committee of Shahid Sadoughi University of Medical Sciences approved this study.
Table 4. Frequency Distribution of AIDS Patients Based on Marital Status in Yazd and Ahvaz, Iran ${ }^{\mathrm{a}}$

\begin{tabular}{lcc}
\hline Marital status & Ahvaz & Yazd \\
\hline Single & $21(32.3)$ & $15(23.1)$ \\
Married & $36(55.4)$ & $32(49.2)$ \\
Divorced & $3(4.6)$ & $12(18.5)$ \\
Widow & $5(7.7)$ & $6(9.2)$ \\
Total & $65(100)$ & $65(100)$ \\
\hline
\end{tabular}

${ }^{\mathrm{a}}$ Values are expressed as No. (\%).

Table 5. Distribution of the Mean and Standard Deviation of Knowledge, Attitude, and Practice Scores of the Participants ${ }^{\mathrm{a}}$

\begin{tabular}{lcc}
\hline Variables & Ahvaz & Yazd \\
\hline Knowledge & $40.68 \pm 2.5$ & $40.31 \pm 3.3$ \\
Attitude & $42.52 \pm 9.05$ & $41.92 \pm 8.8$ \\
Practice & $43.24 \pm 6.08$ & $43.28 \pm 5.3$ \\
\hline
\end{tabular}

${ }^{\mathrm{a}}$ Values are expressed as mean $\pm \mathrm{SD}$.

\section{Results}

The study sample included 65 AIDS patients from Yazd and 65 patients from Ahvaz. Nearly $67.7 \%$ of the participants were men and $32.3 \%$ were female. The level of education in more than $65 \%$ of the patients was primary or middle school in the evaluated cities. As presented in Table 3, the majority of the patients in Yazd (27.7\%) and Ahvaz (38.5\%) were within the age range of 24 - 35 years.

About $40 \%$ of the patients from Yazd and $47.7 \%$ of the patients from Ahvaz were unemployed. Also, nearly $44.6 \%$ and $55.4 \%$ of the patients from Yazd and Ahvaz were married, respectively. Additionally, 70.8\% and 56.9\% of the patients from Yazd and Ahvaz had acquired information about HIV and AIDS in counseling sessions, respectively.

Based on the findings, in $53.8 \%$ of the evaluated cases in Yazd, experience about the disease and social attitude was unsatisfactory, while in $35.4 \%$ of cases, the patients' interaction with healthcare providers was quite good. On the other hand, in $60 \%$ of patients from Ahvaz, experience about the disease and social attitude was satisfactory. Also, the patients' experiences about their interaction with healthcare providers were quite good in $50.8 \%$ of cases.

Based on the findings, the cause of infection in about $60 \%$ and $55.4 \%$ of the patients was injection with contaminated syringes in Yazd and Ahvaz, respectively. The duration of disease was more than five years among patients from Yazd and five years in patients from Ahvaz. The mean scores of awareness, attitude, and performance about the 
prevention of HIV transmission were $40.31 \pm 3.3,41.92 \pm$ 8.8 , and $43.28 \pm 5.3$ in Yazd, respectively. Also, the mean scores of awareness, attitude, and performance of patients about the prevention of HIV transmission were $40.68 \pm 2.5$, $42.52 \pm 9.05$, and $43.24 \pm 6.08$ in Ahvaz, respectively.

\section{Discussion}

The results of the present study showed that the level of knowledge about AIDS was moderate among 27.7\% and $47.7 \%$ of the patients in Yazd and Ahvaz, respectively. This finding was inconsistent with the results reported by Simbar et al. in Isfahan (12), Mohebi et al. in Yasouj (13), Wu et al. (14), Ebadifard et al. in Tehran (15), Mirnejad et al. in Tehran (16), and Lotfipour and Akbarinasab Rafsanjani in Rafsanjan (17). The study by Lotfi Pour Rafsanjani et al. revealed that the knowledge of $89.6 \%$ of students about AIDS and routes of transmission was satisfactory. Also, the results were in line with the findings reported by Sanei Moghadam in Zahedan (18) and Ashrafinia in Kerman (19).

In the present study, the attitude of $10.8 \%$ and $13.8 \%$ of the patients was moderate in Ahvaz and Yazd, respectively. This finding was inconsistent with the results reported by Sanei Moghadam in Zahedan (18) and Vojdani et al. in Shiraz (20). Nevertheless, the findings were similar to the results reported by Bijari in Birjand (21), Mahmoudi and Hossani in Gorgan (22), and Mohebi Nobandegani et al. in Yasouj (13). In the study by Mohebi Nobandegani et al. the attitude of $54.3 \%$ of the participants was positive.

In the present study, $36.9 \%$ and $46.9 \%$ of the patients showed moderate practice with regard to the prevention of HIV transmission in Ahvaz and Yazd, respectively. This finding was in line with the results reported by Gholamotabar Tabari in Babol (23), but inconsistent with the study by Mahmoudi and Hossani in Gorgan (22). According to the results of this study, it seems essential to inform patients on how to function and perform in society in order to prevent AIDS transmission.

In general, patients should be prepared to recognize and practice the right approach in society in order to develop healthy behaviors; therefore, proper training on correct behaviors is necessary. In addition, the important role of experts regarding education on AIDS prevention, promotion of knowledge, attitude, and practice of patients, and ultimately improvement of public health is undeniable in AIDS counseling centers.

The majority of participants in the present study had received their information about HIV from the personnel of AIDS counseling centers. Similar results have been reported in studies by Meshkati et al. (8), Mohebi Nobandegani et al. in Yasouj (13), and van der Ryst in South Africa (24). Nevertheless, in studies by Wu et al. (14) and Ebadifard et al. (15), the most common sources of information were radio and TV. Also, our findings were in contrast with studies performed in Nigeria (25), Spain (26), and Saudi Arabia (27), which showed that mass media, especially radio and $\mathrm{TV}$, was the most common source of information.

The present results showed a significant association between the patients' knowledge and level of education in Yazd and Ahvaz. This finding was similar to the results reported by Meshkati et al. (8), but in contrast with studies by Fido and $\mathrm{Al}$ Kazemi in Kuwait (28) and Farahani et al. in Tehran (29). As the majority of the participants received information about the prevention of AIDS and HIV transmission from counseling centers, these centers should be more involved in education programs. It seems that in near future, AIDS counseling centers need to design and implement training programs related to health interventions by focusing on scientific evaluations and regular, systematic education in the community.

\subsection{Conclusions}

According to the present results, implementation of novel methods is necessary for promoting knowledge among patients and the general population.

\section{Footnotes}

Funding/Support: This study did not receive any financial funding.

Conflicts of Interest: None declared.

\section{References}

1. Stine GJ. AIDS Update, 2003: An Annual Overview of Acquired Immune Deficiency Syndrome. Benjamin-Cummings Publishing Company; 2002.

2. Rokhmah D. The Role of Sexual Behavior in the Transmission of HIV and AIDS in Adolescent in Coastal Area. Proc Environ Sci. 2015;23:99104.

3. Lou LX, Chen Y, Yu CH, Li YM, Ye J. National HIV/AIDS mortality, prevalence, and incidence rates are associated with the Human Development Index. Am J Infect Control. 2014;42(10):1044-8. doi: 10.1016/j.ajic.2014.06.029. [PubMed: 25278391].

4. Naidoo S, Chikte UM. Noma (cancrum oris): case report in a 4-year-old HIV-positive South African child. SADJ. 2000;55(12):683-6. [PubMed: 12608242].

5. Nabunya P, Ssewamala FM. The Effects of Parental Loss on the Psychosocial Wellbeing of AIDS-Orphaned Children Living in AIDSImpacted Communities: Does Gender Matter?. Child Youth Serv Rev. 2014;43:131-7. doi: 10.1016/j.childyouth.2014.05.011. [PubMed: 25067869].

6. Rahimi-Movaghar A, Amin-Esmaeili M, Shadloo B, Noroozi A, Malekinejad M. Transition to injecting drug use in Iran: A systematic review of qualitative and quantitative evidence. Int J Drug Policy. 2015;26(9):808-19. doi: 10.1016/j.drugpo.2015.04.018. [PubMed: 26210009]. 
7. Farahani FK, Cleland J, Mehryar AH. Associations between family fac tors and premarital heterosexual relationships among female college students in Tehran. Int Perspect Sex Reprod Health. 2011;37(1):30-9. doi: 10.1363/3703011. [PubMed: 21478086].

8. Meshkati M, Hajarian A, Mostaajeran M, Neamatolahi SH, Mohammadian B, Baadieyan GH, et al. Knowledge and Attitudes of Health Providers about AIDS. EsfahanIranian J Infect Dis. 2013;60:47-51.

9. Rad M, Hashemipour M, Alizadeh R. Investigation of knowledge and attitudes of patients referring to kerman dental school about AIDS,(SPRING 2006). J Dent Shiraz Univ Med Sci. 2009;10(2):144-52.

10. Zareban I, Heydarnia AR, Rakhshani F, Jabari H, Abd MA. Efficacy of AIDS prevention training program on knowledge, attitude and practice of Chabahar sailors, Iran. J Tabib-Shargh. 2006;8(1):29-36.

11. Marashi T, Foladvand O, Khedmati M, Shahri P. Knowledge and attitude of faculty of health students towards HIV/AIDS. Jundishapur J Health Sci. 2010;2(2):1-14

12. Lolekha R, Boon-Yasidhi V, Leowsrisook P, Naiwatanakul T, Durier Y, Nuchanard W, et al. Knowledge, attitudes, and practices regarding antiretroviral management, reproductive health, sexually transmitted infections, and sexual risk behavior among perinatally HIV-infected youth in Thailand. AIDS Care. 2015;27(5):618-28. doi: 10.1080/09540121.2014.986046. [PubMed: 25506754]

13. Mohebi Nobandegani Z, Mobaraki A, Afrasiabi-Far A, Moshfe AA. Knowledge and attitude of health personnels working in educational-treatmental hospitals-Yasuj city regarding AIDS. Ar maghane Danesh. 2003;8(2):47-54.

14. Wu HC, Ko NY, Shih CC, Feng MC. [HIV/AIDS: an exploration of the knowledge, attitude, infection risk perceptions, and willingness to care of nurses]. Hu Li Za Zhi. 2014;61(5):43-53. doi: 10.6224/JN.61.5.43. [PubMed: 25271032].

15. Ebadifard AF, Feshraki M, Hedaiat M, Mosavyanpoor MK. Evaluating high school HIV/AIDS education: implications of intervention. J Hakim. 2003;6(2):53-60.

16. Mirnejad R, Kiani J, Jeddi F, Alaedini F. Knowledge, attitude and practice of Iran University of Medical Sciences Students about AIDS. Iran J Nurs. 2009;21(56):17-26.

17. Lotfipour A, Akbarinasab J. Knowledge, attitude and practice of nonmedical students to the ways of transmission and prevention of AIDS in Rafsanjan city. Iran J Nurs Res. 2011.

18. Sanei ME, Khosravi S, Abiz A, Marashi N, NAHR KM, Sarhadi I. Knowledge, attitude and practice toward HIV/AIDS among students of Zahedan Islamic Azad University. J Blood. 2011;7(4):206-13.

19. Ashrafinia F, Janani L, Khajeh Kazemi R, Dastoorpour M. The Relationship between fear of AIDS with childbearing age women knowledge and attitude toward AIDS. Razi J Med Sci. 2014;20(117):76-84.

20. Vojdani M, Farzin M, Derafshi R, Safari A, Madadi G. Knowledge, attitude and performance of dentists in Shiraz in relation to AIDS. J Isfahan Dent School. 2012;8(4).

21. Bijari B, Abassi A, Sharifzade G, Salehi S. Effects of health education program on knowledge and attitude of barbers and beauticians in Birjand about AIDS:(A Short Report). J Rafsanjan Univ Med Sci. 2012;11(5):489-94.

22. Mahmoudi GR, Hossani SA. Knowledge, attitude and performance of barbers about AIDS prevention.J Gorgan Univ Med Sci. 2000;2(1):26-32.

23. Gholamotabar Tabari M, Moslemi L, Malekzadah RA. Comparison of knowledge and practice of male and female high school students about AIDS in Babol city. J Fam health Azad Univ Sari. 2013;1(4):21-8.

24. van der Ryst E, Joubert G, Steyn F, Heunis C, le Roux J, Williamson C. HIV|AIDS-related knowledge, attitudes and practices among South African military recruits. South Afr Med J. 2001;91(7):587-91.

25. Arowojolu AO, Ilesanmi AO, Roberts OA, Okunola MA. Sexuality, contraceptive choice and AIDS awareness among Nigerian undergraduates. Afr J Reprod Health. 2002;6(2):60-70. [PubMed: 12476717].

26. Kerr CI, Horrocks MJ. Knowledge, values, attitudes and behavioural intent of Nova Scotia nurses toward AIDS and patients with AIDS. Can J Public Health. 1989;81(2):125-8.

27. Al-Ghanim SA. Knowledge and attitudes toward AIDS/HIV in Saudi Arabia. S Med J. 2005;26(5):812-8.

28. Fido A, Al Kazemi R. Survey of HIV/AIDS knowledge and attitudes of Kuwaiti family physicians. Fam Pract. 2002;19(6):682-4. [PubMed: 12429674].

29. Farahani FK, Shah I, Cleland J, Mohammadi MR. Adolescent males and young females in tehran: differing perspectives, behaviors and needs for reproductive health and implications for gender sensitive interventions. J Reprod Infertil. 2012;13(2):101-10. [PubMed: 23926532]. 